\title{
A TUTELA DO CONSUMIDOR EM JUÍZO EM FACE DA RESOLUÇÃO No 400 DA ANAC SOB A ÓPTICA DA LEI ANTITRUSTE
}

\author{
Fábio Campelo Conrado de Holanda \\ Doutor em Ciência Política pela Universidade Federal do \\ Rio Grande do Sul (UFRGS). Mestre em Direito pela \\ Universidade Federal do Ceará (UFC). Professor do \\ Mestrado em Relações Privadas, Sociedade e \\ Desenvolvimento do Centro Universitário 7 de Setembro \\ (UNI7). Procurador Federal. \\ fabiodeholanda@yahoo.com.br

\section{Jéssica Mendes Dutra} \\ Mestranda em Relações Privadas, Sociedade e \\ Desenvolvimento pela UNI7. \\ jessicamendes@hotmail.com.br
}

RESUMO: O objetivo geral deste artigo consiste em investigar a tutela coletiva do consumidor em juízo no Brasil sob o enfoque específico de ação civil pública que discute a alteração das regras do transporte aéreo. Procedeu-se com o estudo dos institutos de defesa do consumidor ligados às recentes alterações das regras do transporte aéreo, reconhecendo-se também que os princípios de defesa da concorrência têm como pano de fundo, além da aplicação do princípio constitucional da livre iniciativa, a defesa do destinatário final, a tutela do consumidor, dada a tendência de consolidação de oligopólios capazes de aguçar a vulnerabilidade técnica, econômica e informacional em desfavor do player fraco dessa relação. A metodologia utilizada foi a análise de documentos e da bibliografia especializada sobre o tema, além da análise de julgados. No caso concreto que se pretendeu analisar, viu-se que a retórica defendida pelo órgão de defesa do consumidor na ação coletiva foi no sentido de que a Agência Reguladora deveria restringir a liberdade do mercado de transporte aéreo proposta no Resolução $n^{\circ} 400$, a fim de supostamente defender este player fraco da relação, haja vista a provável exploração econômica que este virá a sofrer mediante a desregulação dos serviços. Entendeu-se no presente arrazoado, porém, que a confessada desregulação do serviço de transporte aéreo, ao invés de fragilizar a condição do passageiro e aguçar a vulnerabilidade peculiar da respectiva relação de consumo, poderá ter efeitos diametralmente opostos, na medida em que a ampliação da concorrência tenderá a trazer mais opções de mercado, com passagens mais baratas, inclusive, de modo a contemplar os variados segmentos e perfis dos contratantes (tanto os passageiros quanto as empresas), fazendo que com seja possível a retomada de crescimento do setor, cuja manutenção das premissas normativas anteriores (concebidas historicamente em outra época, registre-se), impingia excessiva oneração aos contratantes.

PALAVRAS-ChAVE: Direito Privado. Tutela coletiva do consumidor em juízo. Transporte aéreo. Livre concorrência. 
A tutela do consumidor em juízo em face da Resolução nº 400 da ANAC sob a óptica da lei antitruste

The guardianship of the consumer in court considering ANAC's Resolution 400 from the standpoint of antitrust law treatment

ABSTRACT: The purpose of this article is to investigate the consumer's collective guardianship in Brazilian courts focusing specifically on Public Civil Actions that discuss the modifications in air transportation rules. In the procedure, consumer's defense institutes connected with the recent changes on the air transport's rules have been studied, also recognizing that the principles of competition policy have as background, besides the application of the constitutional principle of free enterprise, the defense of the final recipient, consumer's guardianship, given the consolidation's trend of oligopolies capable of sharpening technical, economic and informational vulnerability in detriment of the weak player from this relationship. The methodology adopted was the analysis of documents and the specialized bibliography on the subject, besides the analysis of judgments. In the specific case that was intended to be analyzed, it was seen that the rhetoric defended by the consumer defense organization in collective action was in the sense that the Regulatory Agency should restrict the freedom of the air transport market proposed in Resolution 400, in order to supposedly defend this weak player of the relationship, given the probable economic exploitation that this will suffer through the deregulation of services. It is understood, however, that the confessed deregulation of the air transport service, instead of weakening the passenger's condition and sharp the peculiar vulnerability of the consumption's respective relation, could have diametrically opposed effects, inasmuch as the expansion competition will tend to bring more market options, with cheaper airfares, including, a way to contemplate the various segments and profiles of contractors (both passengers and companies), making possible to resume growth in the sector, whose maintenance of the previous normative premises (historically conceived in another time, registering), imposed excessive burden on contractors.

KEYWORDS: Private Law; Collective guardianship of the consumer in court; Air transportation; Free competition.

\section{INTRODUÇÃO}

$\mathrm{O}$ interesse pelo estudo do presente tema se justifica primeiramente por se tratar de recentíssima novidade legislativa trazida à tona através Resolução $n^{\circ} 400$, de 13 de dezembro de 2016, oriunda da Agência Nacional de Aviação Civil (ANAC), ainda sem reflexão específica por parte da comunidade acadêmica, em cuja ambientação um dos autores se insere, tanto no aspecto docente, dado o aprofundamento dos estudos relacionados com os institutos de direito privado, notadamente em relação aos desafios das relações consumeristas na contemporaneidade, quanto, no âmbito forense, através do acompanhamento de lides envolvendo particulares e o Estado, sob o pálio do microssistema das relações de consumo que, no caso em liça, se relaciona com a repercussão judicial da referida norma que altera as regras do transporte aéreo de passageiros.

O objetivo geral do presente artigo é analisar em que medida as alterações empreendidas pela Agência Nacional de Aviação Civil se inserem no contexto de defesa do consumidor do transporte aéreo no Brasil. O objetivo específico se revela na análise circunstanciada dos argumentos trazidos pelos órgãos de proteção do consumidor em juízo, com a avaliação teórica de estarem ou não adequados às normas deste microssistema de direito privado.

A metodologia que se pretende adotar no enfrentamento do tema é a análise de documentos oficiais a par de seu cotejo com a legislação de espécie e a dialética processual que se instau- 
rou acerca deste recentíssimo assunto relacionado com as relações privadas envolvendo os grandes conglomerados das empresas de transporte aéreo, os consumidores e o órgão de regulação estatal.

Inicialmente, cumpre esclarecer o leitor, por apego à didática, que até o momento da elaboração do presente artigo, existiam três ações civis públicas deflagradas com o propósito de impugnar alguns dispositivos da referida norma setorial, sendo a primeira delas ajuizada na Seção Judiciária do Estado do Ceará e as outras duas no Estado de Pernambuco e no Distrito Federal. Importante esclarecer, ainda, que não existia decisão de mérito em nenhuma das lides até então.

Por meio da Ação Civil Pública (ACP) no 0816363-41.2016.4.05.8100, em curso na $10^{\mathrm{a}}$ Vara Federal do Ceará, o Departamento Municipal de Proteção e Defesa do Consumidor (PROCON), órgão integrante do Sistema Municipal de Defesa do Consumidor (ut Lei Complementar $\mathrm{n}^{\circ} 187$, de $1^{\circ}$ de dezembro de 2014), ajuizou demanda em desfavor da ANAC postulando a revogação de alguns dispositivos da Resolução (quais sejam, os artigos $3^{\circ} ; 4^{\circ}, \S 2^{\circ} ; 9^{\circ} ; 11$ e 19).

A ACP no 0810187-28.2016.4.05.8300, em trâmite na $9^{\text {a }}$ Vara Federal de Pernambuco, protocolada também pelo PROCON em desfavor da ANAC, encampa impugnações à Resolução com base nos artigos $5^{\circ}, \mathrm{IV} ; 9^{\circ}$, caput; $12, \S 1^{\circ}, \mathrm{I} ; 13, \S 1^{\mathrm{o}} ; 14$, caput e $\S 2^{\mathrm{o}} ; 15, \S 1^{\mathrm{o}}$ e $32, \S 2^{\mathrm{o}}$, I e II.

Resumidamente e para fins de contextualizar o leitor sobre o desenvolvimento do texto, afirma-se na exordial desta ação judicial que "o despacho de bagagem é gratuito para malas de até 23 (vinte e três) quilos em voos domésticos e para duas malas de até 32 (trinta e dois) quilos, cada uma, em voos internacionais"; e que "os fornecedores poderão, de maneira arbitrária e sem qualquer controle, alterar o limite de peso para menor, podendo o fazer sob qualquer justificativa", dentre outras ilações.

Por fim, em relação à ACP n ${ }^{\circ}$ 0000752-93.2017.4.01.3400 (pendente na $4^{\mathrm{a}}$ Vara Federal do Distrito Federal), manejada pelo Conselho Federal da Ordem dos Advogados do Brasil (CFOAB) em desfavor da ANAC, postulou-se a anulação dos artigos 13, caput; 15 e 45, da Resolução, com o viso de fazer a Agência se abster de autorizar a cobrança por bagagem dentro dos limites da franquia estabelecidos na legislação anterior.

Pois bem, apresentadas algumas premissas em que se fundará o debate acadêmico no presente arrazoado, com induvidosa problemática de âmbito nacional, ilustrar-se-ão a seguir alguns aspectos teóricos relacionados com a tutela coletiva do consumidor em juízo, sua proteção sob o prisma do direito antitruste, além de reflexões sobre a Política Nacional das Relações de Consumo que, dentre outros princípios, assenta a necessidade de harmonização dos interesses entre fornecedores e consumidores, de modo a não privilegiar a defesa irrestrita do vulnerável de tal sorte que aniquile a atuação empresarial daqueles.

As críticas que o artigo enfrentará serão suficientes contribuições para o avanço e tratamento de tema tão caro para quem, como os autores, fomentam a dialética acerca dos direitos fundamentais e dos institutos de direito privado quando do enfrentamento de temas contemporâneos. 


\section{CONSIDERAÇÕES SOBRE A TUTELA COLETIVA DO CONSUMIDOR EM JUÍZO}

Sem a preocupação de verticalizar o debate sobre a já repisada diferença doutrinária entre os direitos difusos, coletivos e individuais homogêneos, que tem a importante valia de apresentar ao estudante da tutela judicial coletiva os diversos envolvimentos e graus de generalidade de pessoas que podem se unir em determinadas relações jurídicas, interessa nesse momento tangenciar alguns aspectos teóricos relacionados com o tratamento judicial de interesses dos consumidores.

A tutela do consumidor em juízo não se resume à mera disciplina processual inserida no CDC, pois deve contemplar a evolução desse segmento do direito privado que trouxe princípios próprios na disciplina da matéria. A propósito do tema que se pretende debater, relacionado com o tratamento das regras do transporte aéreo aos passageiros em geral, pertinente se afigura tangenciar a lógica dos contratos de adesão, em cujas vantagens se insere permitir a facilitação da aquisição de serviços pela sua operacionalidade mais cômoda, contrapondo-se à mitigação da autonomia da vontade (na medida em que as cláusulas seriam estabelecidas previamente, sem possibilidade de negociação caso a caso).

Em contraponto à impossibilidade de os celebrantes tergiversarem sobre os termos da avença por ocasião desta modalidade contratual, aviltou-se a necessidade de revisão de alguns pactos, não apenas nas hipóteses excepcionais da teoria da imprevisão, mas também para afastar a aplicação de cláusulas abusivas, relativizando o dogma da intangibilidade do contrato, vigente no período clássico da teoria contratual, e mais recentemente, no Brasil, através do histórico Código de Beviláqua (1916).

No direito brasileiro, a Lei de Ação Popular (Lei no 4.765/65), a da ACP (Lei n $7.347 /$ 85) e o CDC (Lei $\left.n^{\circ} 8.078 / 90\right)$ retratam a preocupação do legislador em disciplinar a tutela de direito coletivos (em sentido amplo), principalmente nas questões ambientais e consumeristas, ínsitas à pós-modernidade. A despeito da cronologia das leis de ação popular e da ACP, coube ao CDC trazer o conceito legal de direitos difusos e coletivos (em sentido estrito) e acrescentar a eles os direitos individuais homogêneos.

No caso dos consumidores que se julguem supostamente prejudicados pela alteração das regras impugnadas nas ações coletivas em epígrafe, que é fruto de uma mentalidade de desregulação já instituída na maioria dos países do Ocidente, corolário do amadurecimento da livre concorrência e do liberalismo de mercado no segmento da aviação civil, identifica-se uma nítida expressão da tutela coletiva do consumidor em juízo.

Os sistemas processuais da defesa do consumidor e da Lei $\mathrm{n}^{\circ} 7.347 / 1985$ constituem um "microssistema processual coletivo", nas palavras de Leonardo de Medeiros Garcia (2016, p. 454), utilizando-se subsidiariamente o Código de Processo Civil (CPC). Por conseguinte, no caso da desregulação das normas de transporte aéreo no Brasil, verifica-se que as dificuldades enfrentadas no embate entre o mercado livre e defesa do consumidor recomendam um modelo diverso de formatação das lides de natureza coletiva, capaz de contemplar direitos que extrapolam o espectro individual.

Com lastro no princípio do máximo benefício da tutela jurisdicional coletiva comum, orienta-se a não limitar as hipóteses de cabimento desse instrumento catalizador dos interesses individuais representados, de modo a evitar novas demandas que possuam a mesma causa de pedir. Deve-se, nesta linha de raciocínio, perseguir resultados capazes de conduzir a uma certeza jurídica emergente do julgamento requestado pelas partes. 
Verifica-se, ainda, que em face do inerente ativismo judicial na condução destas ações, a listagem dos processos coletivos procedida na introdução do presente artigo facilitará o mapeamento do entendimento judicante que servirá de farol na consolidação da tese vencedora sobre as pretendidas mudanças nos contratos de transporte aéreo que foram anunciadas, cuja tônica é o aprimoramento da liberdade de mercado e estímulo da concorrência entre as companhias aéreas.

Politicamente, também se verificam vantagens na priorização da solução de determinados conflitos no viés coletivo, haja vista a facilidade do acesso à justiça e o menor dispêndio econômico, capaz de tornar o mister do Poder Judiciário mais racional dada a aptidão de neutralizar as vantagens dos litigantes habituais e dos mais fortes.

Em relação à legitimidade do PROCON para iniciar as demandas coletivas na conformidade do que se noticiou em epígrafe (considerando que a do CFOAB é inconteste, conforme se extrai do figurino constitucional), convém identificar na jurisprudência do Superior Tribunal de Justiça (STJ) importantes precedentes. No AgRg no REsp. 512.382/DF (da relatoria do Ministro Antonio Carlos Ferreira, da Quarta Turma e julgado em 14.08.2012), decidiu-se que tal órgão era legitimado à propositura da ação visando questionar o reajuste de mensalidades de plano de saúde. No REsp. 200.827/SP (da relatoria do Ministro Carlos Alberto Menezes Direito, da Terceira Turma e julgado em 26.08.2002), já havia se pronunciado no sentido de acolher a legitimidade da Coordenadoria de Proteção e Defesa do Consumidor para questionar a cobrança indevida de taxas pelas administradoras de imóveis.

Sob o ponto de vista da regularidade formal, tanto no aspecto da legitimidade ativa, quanto da adequação da via instrumental eleita, portanto, identificam-se como legítimas as pretensões deduzidas nas ACP's sub oculi.

Na esteira do pensamento de Gregório Assagra de Almeida (2003, p. 76-90), o juiz deve buscar facilitar o acesso à justiça, na medida do possível, superando vícios processuais em razão da função social de desvendar o mérito da demanda coletiva na busca da efetivação dos valores democráticos, recomendando-se que ao invés de extinguir a ação por ilegitimidade da parte autora, por exemplo, publique editais convidando outros legitimados a aderir na angularização do processo.

É o espírito de enfretamento meritório das grandes questões que emergem da vida gregária, que se espera esteja incorporado na dinâmica do Poder Judiciário. Adiante com o debate.

\section{A PROTEÇÃO DO CONSUMIDOR SOB O PRISMA DO DIREITO ANTITRUSTE.}

$\mathrm{Na}$ esteira do pensamento do sociólogo polonês Zygmunt Bauman (2011, p. 55-79), a sociedade de consumo contemporânea tem por base a premissa de satisfazer os desejos humanos de uma forma que nenhuma outra sociedade do passado pôde realizar, num tempo cada vez mais curto e de formas cada vez mais indefinidas, inconstantes, instantâneas. Consolidou-se a sociedade do consumo de massa.

É característico desta pós-modernidade ${ }^{1}$ a inexistência de tempos contínuos no que se refere ao ciclo de vida dos produtos e das decisões humanas, observando-se que os seus ciclos

\footnotetext{
1 Destaque-se que se utilizou inicialmente da expressão pós-modernidade (BAUMAN, 2011) e que, posteriormente, veio a substituir pelo conceito de modernidade líquida, no livro homônimo. Esse conceito de sociedade pós-moderna é também utilizado por Baudrillard, (2008). Esse, também, é um termo que foi bastante utilizado por Ulrich Beck, que
} 
de vida estão cada vez menores (afinal, eram fabricados para durarem por longo período e hoje são substituídos num piscar de olhos, por outros supostamente mais modernos, mais úteis e que trarão, hipoteticamente, mais felicidade ${ }^{2}$ ao seu possuidor).

No que diz respeito às viagens de avião, mais especificamente, a despeito dos números em queda no último ano (7,8\% menor do que 2015$)$, é fato que a população brasileira experimentou nos dez anos anteriores um significativo incremento na opção pelo transporte aéreo ${ }^{3}$, tendo havido considerável capilaridade destes deslocamentos entre as pessoas das diversas faixas econômicas. $^{4}$

A ambientação com essa nova modalidade de transporte teve o condão de incrementar o consumo de massa, inserindo os consumidores em geral nos riscos contratuais que são peculiares desta modalidade de avença, potencializada pelo amplo acesso à internet. Diante dessa realidade, não se pode olvidar que o consumidor está cada vez mais vulnerável em face de um mercado cada vez mais organizado, globalizado, no qual há uma predominância de grandes empresas e de grandes monopólios ou oligopólios compostos fortes grupos empresariais (onde se incluem as empresas aéreas).

Antecipadamente aos esclarecimentos constantes no tópico 4 do presente artigo, é bom que se diga que o Comando da Aeronáutica, órgão responsável pela regulação da aviação civil no Brasil antes da criação da ANAC, tinha como principal objetivo a segurança nacional, sobretudo na defesa das fronteiras, sendo de notar, à época, a incipiência da regulação de cunho econômico, voltada à defesa da concorrência. Estava-se diante de outro contexto histórico.

No que se refere à doutrina de escolha do consumidor, registra-se intenso debate doutrinário travado entre Robert Lande (1997) e Robert Bork (1993), nos Estados Unidos, no qual o primeiro defendia que o objetivo principal da política antitruste seria a garantia do direito de escolha do consumidor, enquanto o segundo advogava que o principal desiderato do legislador ao promulgar a lei antitruste seria a busca pela eficiência do mercado.

Independente da primazia de uma ou outra tese, pode-se afirmar que tanto a liberdade de escolha quanto a eficiência econômica são complementares ou interdependentes, afinal, de que vale a liberdade de escolha se não houver eficiência econômica? De que adianta a eficiência econômica se o consumidor não for livre para a escolha que lhe convier?

No Brasil, corolário da previsão constitucional da defesa da concorrência (um dos princípios gerais da atividade econômica, com assento no artigo 170, inciso IV, da Constituição Federal de 1988 - CF/88), valida-se a legislação infraconstitucional que objetiva a concretização desta norma, como a Lei $n^{\circ}$ 12.529/2011, que estabeleceu alguns controles e a Lei n 8.137/1990, que criminalizou diversas condutas.

A sociedade de consumo de massa tem como grande desafio a conciliação de valores, supostamente antagônicos, como o livre acesso ao consumo, a defesa da concorrência e a defesa do consumidor. $\mathrm{O}$ artigo $173, \S 4^{\circ}$, da $\mathrm{CF} / 88$, estabeleceu que a lei reprimirá o abuso do poder

assinalou no prefácio de sua mais renomada obra: “[o] tema deste livro é o discreto prefixo ‘pós'. Ele é a palavra chave de nossa época" (BECK, 2011). Pode-se afirmar, guardadas algumas peculiaridades de cada obra, que os referidos autores ao falarem sobre a sociedade pós-moderna, estão a falar sobre a sociedade contemporânea, o aqui e o agora.

2 Conforme ressalta Jean Baudrillard: "é no consumo do excedente e do supérfluo que tanto o indivíduo como a sociedade, se sentem não só existir, mas viver” (BAUDRILLARD, 2008. p. 40). Esse viver para consumir é o que traz a felicidade momentânea ao consumidor.

3 Nota Técnica ANAC n ${ }^{\circ} 11 / 2016 /$ GEAC/SAS.

${ }^{4}$ Com efeito, nos anos 2000, pouco mais de 35 milhões de passageiros viajavam por ano, ao passo que atualmente são quase 120 milhões, conforme Anuário Estatístico da ANAC de 2015. 
econômico que vise à dominação dos mercados, à eliminação da concorrência e ao aumento arbitrário dos lucros, reforçando o compromisso do Estado com a proteção do consumidor.

É bom que se diga que o constituinte originário não trouxe o conceito de livre concorrência, deixando ao legislador ordinário e ao intérprete tal incumbência, que a depender do contexto em que são aplicadas e de acordo com a visão de quem o aplica, pode induzir circunstancialmente a proteção do consumidor e os objetivos das políticas antitruste.

A propósito, a Lei $n^{\circ} 12.529 / 2011$ menciona o termo consumidor em seu artigo $1^{\circ}$, ao incluir sua defesa entre os princípios de defesa da concorrência, entretanto, não traz, em nenhum momento, a definição ou conceito de consumidor, no entanto, o artigo 115 determina a aplicação subsidiária do CDC. Nesse diapasão, há quem defenda que o conceito de consumidor pode ser unificado, para efeito de aplicação de ambas as legislações.

Conforme leciona Rizzato Nunes (2012. p. 102), a livre concorrência é essencialmente uma garantia do consumidor e do mercado, significando, portanto, que o produtor/fornecedor tem de oferecer ao consumidor produtos e serviços melhores do que os de seus concorrentes. Essa obrigação é posta ad infinitum, de forma que sempre haja melhora. Evidente que esse processo de concorrência se faz não só pela qualidade, mas, principalmente, pelo preço. $\mathrm{O}$ forte elemento concorrencial na luta pelo consumidor é o binômio qualidade/preço.

Autoriza-se inferir, a priori, que a concorrência tem papel fundamental em dois aspectos relevante para a melhoria do bem-estar do consumidor: preço e qualidade. Mas, se é justamente por meio da defesa da concorrência que se garante um mercado com vários fornecedores/produtores, não se pode deixar de mencionar um terceiro aspecto relevante que são os princípios antitrustes de garantia da liberdade de escolha. Aqui, garantir a liberdade de escolha é assegurar que sempre haverá no mercado um satisfatório número de players concorrendo em igualdade de condições.

Relacionado com o princípio da autonomia da vontade, o direito de escolha é expressamente mencionado no artigo $6^{\circ}$, inciso II, do CDC ("a educação e divulgação sobre o consumo adequado dos produtos e serviços, assegurada a liberdade de escolha e a igualdade nas contratações"), sendo dever do órgão de regulação, no presente estudo, preservar o necessário protagonismo volitivo do consumidor em todas as fases da relação de consumo (não apenas na celebração da avença e mesmo após o término da execução), sempre o fazendo de modo inteligível, a par do desenvolvimento do mercado para as companhias aéreas.

De certa forma, há consenso na afirmativa de que os consumidores são beneficiados pela concorrência pois ela acarreta menores preços (MAGALHÃES, 1976, p. 3-5), pois quanto maior a qualidade e a diversidade de produtos e serviços colocados à disposição da sociedade (FONSECA, 2001. p. 78), liberdade de escolha, como pressuposto do direito de acesso ao consumo (MALARD, 1997, p. 134).

$\mathrm{Na}$ relação entre defesa do consumidor e normas concorrenciais um ponto deve ficar claro, conforme aduz Calixto Salomão Filho (2003. p. 81), "o fato de o consumidor ser o destinatário econômico final das normas concorrenciais não o transforma em destinatário jurídico direto das mencionadas normas", afinal, muitas vezes é apenas através da proteção da instituição "concorrência" que seu interesse será protegido. O posicionamento do autor supracitado é no sentido de que a legislação de defesa da concorrência tem como foco direto a proteção do mercado e indiretamente a proteção do consumidor. 


\section{A ATUAÇÃO DAS AGÊNCIAS REGULADORAS NA PROTEÇÃO DO CONSUMIDOR E OS PRINCÍPIOS REITORES DA RESOLUÇÃO No 400 DA ANAC.}

Há que se esclarecer que as agências reguladoras não são órgãos de defesa do consumidor e, assim, não integram o Sistema Nacional de Defesa do Consumidor. A regulação deve ser um ponto de equilíbrio baseado na harmonização dos interesses dos fornecedores e dos consumidores, assentada na viabilização e dinamização do serviço ou produto regulado. É verdade, registrese, que as agências reguladoras não podem desrespeitar as leis de proteção do consumidor, devendo refleti-las em suas normas de regulação (PFFEIFFER, 2016, p. 91).

$\mathrm{Na}$ esteira do artigo $7^{\circ}$, caput, do $\mathrm{CDC}$, a teoria do diálogo das fontes teve sua utilidade emergida por ocasião da promulgação do Código Civil de 2002 (CC-02), quando surgiram indagações acerca do possível conflito entre as normas dos dois códigos. A solução não é excludente, mas conciliadora e, segundo Cláudia Lima Marques (2005, p. 78), "as normas do CC-02 podem ser aplicadas às relações de consumo como normas gerais, subsidiárias e no que couber, ou quando especifiquem sua aplicação ao caso concreto".

A proteção do consumidor transcende a normatização do CDC, devendo haver uma simbiose de outras fontes normativas capazes de tutelar a flagrante desigualdade de posições na assunção das obrigações consumeristas, notadamente quando se está diante de um cenário de poucas empresas que detêm a condição de fornecedoras dos serviços de transporte aéreo de passageiros. 5

Enquanto exemplo de normais setoriais que foram sindicadas judicialmente por alegados desacertos com a legislação consumerista, tem-se que a Agência Nacional de Telecomunicações (ANATEL) editou resolução que desrespeitava preceito do CDC e, assim, era inválida. É que o parágrafo único da Resolução $\mathrm{n}^{\circ} 85$ da Agência determinava, em caso de cobrança indevida no serviço de telefonia fixa comutada, a devolução do mesmo valor cobrado mais os respectivos encargos, o que contrariava o texto expresso do artigo 42, parágrafo único, do CDC. A norma foi posteriormente revogada pela ANATEL através da Resolução $n^{\circ} 426$, de 9.12.2007, cujo artigo 98, parágrafo único, determina a devolução em dobro ao usuário que efetuar o pagamento de quantia cobrada indevidamente.

Noutro caso, alinhando-se como as normas de defesa do consumidor, a Resolução $n^{\circ} 567$, de 24.5.2011, da mesma ANATEL alterou regulamentos de diversos serviços a fim de adequálos às disposições do Decreto $\mathrm{n}^{\circ}$ 6.523, de 31.7.2008, que regulamentou o CDC para fixar normas gerais sobre Serviço de Atendimento ao Consumidor (SAC).

Vê-se, portanto, que já existe um histórico de debates judiciais em que se digladiam as normas oriundas das Agências Reguladoras no Brasil e a legislação de espécie voltada à defesa do consumidor. Antes de se verticalizar o debate sobre as alterações intentadas pelas regras do

\footnotetext{
5 Não é demais lembrar do caso em que normas setoriais conflitavam com normas do CDC no caso de indenização por extravio de bagagem em transporte aéreo, onde todos os diplomas legais determinavam a indenização, mas o ponto controverso era o quantum indenizatório, pois enquanto o CDC estabelecia a regra da efetiva reparação (artigo $6^{\circ}$, VI) tanto o Código Brasileiro de Aeronáutica quanto a Convenção de Varsóvia impunham limites ao valor, tarifando-o. O STJ (REsp. 1289629) decidiu que prevalece a regra do CDC uma vez que se informe, no conhecimento de transporte, o conteúdo da mercadoria transportada. O STF (RE 297901 e está rediscutindo na repercussão geral no RE 636331), porém, julga diferente (exceto quanto ao eventual dano moral) a matéria quando há transporte aéreo internacional, entendendo prevalecer a Convenção de Varsóvia.
} 
transporte aéreo, convém que se tangencie o histórico normativo do transporte aéreo, preparando o enfrentamento da atuação da ANAC e sua Resolução n ${ }^{\circ} 400$.

A Convenção de Varsóvia, datada de 1929, foi a primeira norma a tratar da aviação. Naquele momento, a proteção do transportador, com a mitigação de sua responsabilidade, era a tônica da regulação do setor. Tal orientação foi mudando nas décadas seguintes (Convenções de Haia, em 1955; Montreal, em 1966; Guadalajara, em 1971; e novamente Montreal em 2006), com a ampliação dos limites indenizatórios e a maior responsabilização do fornecedor, cuja imputação passou a ser objetiva.

O setor aeronáutico no Brasil, antes da criação da ANAC, se afastava do arcabouço típico do surgimento das outras Agências. Neste segmento, a prestação dos serviços aéreos não era monopólio estatal e tampouco executado, em sua maior parte, diretamente pela Administração Pública. O setor privado, antes mesmo da existência da ANAC, já provia a demanda por serviços aéreos. Muitos dos leitores se recordarão das companhias Varig, Vasp, e Transbrasil, por exemplo.

Assim, o surgimento da $\mathrm{ANAC}^{6}$, diferentemente do surgimento de outras agências reguladoras, não foi precedido da desestatização de serviço público ou privatização de empresa pública prestadora de serviços públicos ou exploradora de atividade econômica. Antes mesmo da criação da ANAC, já eram desempenhadas as atividades de fiscalização e de definição dos contornos das atividades de aviação civil, as quais estavam a cargo, à época, do Comando da Aeronáutica, nos termos da Lei Complementar $n^{\circ}$ 97, de 9 de junho de 1999.

Não à toa, parte do conteúdo que se disciplinou na Resolução ANAC n ${ }^{\circ} 400$ estava tratado em normas editadas pelo referido órgão militar (Portaria $n^{\circ} 767 / C G-5$, de 13 de novembro de 2000). É bom que se esclareça, no entanto, que o cenário da época e, consequentemente, o escopo da regulação eram bastante diversos da finalidade regulatória atual.

Quanto à vulnerabilidade dos consumidores neste segmento de mercado, é fato que nem as associações, nem os órgãos de proteção ao consumidor dispõem de conhecimentos técnicos para compreender e participar ativamente do processo regulatório, não tendo, inclusive, recursos financeiros para a contratação de especialistas. De outro lado, os fornecedores de serviços públicos regulados possuem conhecimentos técnicos e capacidade econômica superior não só em relação aos consumidores, mas também em relação às próprias agências reguladoras. Diante disso, a iniciativa da ANAC de promover audiências públicas antes da edição da norma em debate, teve o condão de atenuar tais assimetrias.

A Resolução no 400 está ancorada na Nota Técnica ANAC nº 11/2016/GEAC/SAS, de 17 de maio 2016, que contemplou o estudo sobre os possíveis efeitos da desregulamentação da franquia de bagagem despachada no mercado de transporte aéreo, fruto da Agenda Regulatória da ANAC para o biênio 2015-2016, aprovada por meio da Portaria no 2975/DIRP, de 10 de dezembro de 2014. Segundo o item 14 da Nota Técnica, as medidas de flexibilização das condições de prestação dos serviços de transporte aéreo têm proporcionado o desenvolvimento desses serviços, através da ampliação da concorrência entre as empresas do setor e inúmeros benefícios aos passageiros a médio e longo prazo.

Por fim, é importante registrar que se inserem como medidas de desregulamentação: a implantação do regime de liberdade tarifária em voos domésticos e internacionais no Brasil; a

\footnotetext{
6 A competência da ANAC sobre a matéria exsurge do disposto no Código Brasileiro de Aeronáutica (artigo 193) e é confirmada pelo artigo $8^{\circ}$, incisos IV e X, da Lei $\mathrm{n}^{\circ} 11.182$, de 27 de setembro de 2005. O poder de elaborar normas nessa matéria é intrínseco ao poder regulador conferido à Agência, sem o qual não poderia exercer a finalidade, definida no artigo $2^{\circ}$ da lei de criação, de regular e fiscalizar as atividades de aviação civil.
} 
livre iniciativa para a constituição de novas empresas aéreas; e a liberdade de oferta de voos em qualquer linha aérea no país. A referida Nota Técnica projetou os seguintes benefícios com a norma: a ampliação da concorrência no setor; a criação de novas empresas aéreas; a expansão da oferta de voos; a diversificação dos serviços e de tarifas; a melhoria da eficácia operacional; a inovação; a redução das tarifas; o incremento da demanda por transporte aéreo; e a inclusão social.

\section{A DIALÉTICA CIRCUNSTANCIADA DO MÉRITO DA ACP N ${ }^{0}$ 0816363-41.2016.4.05.8100}

Por meio da Ação Civil Pública (ACP) no 0816363-41.2016.4.05.8100, em curso na $10^{\mathrm{a}}$ Vara Federal do Ceará, o Departamento Municipal de Proteção e Defesa do Consumidor (PROCON), órgão integrante do Sistema Municipal de Defesa do Consumidor (ut Lei Complementar $\mathrm{n}^{\mathrm{o}} 187$, de $1^{\circ}$ de dezembro de 2014), ajuizou demanda em desfavor da ANAC postulando a revogação de alguns dispositivos da Resolução (quais sejam, os artigos $3^{\circ} ; 4^{\circ}, \S 2^{\circ} ; 9^{\circ} ; 11$ e 19).

Tais normas, segundo o demandante, impingiriam ao player fraco dessa relação (o consumidor) que custeasse as despesas com o transporte de sua bagagem, resultando em elevação significativa do preço final do serviço, o que teria o condão de se configurar prática abusiva, capitulada no artigo 39, incisos V e X do Código de Defesa do Consumidor (CDC).

Em síntese, entendeu-se que ao estabelecer que "as multas contratuais não poderão ultrapassar o valor dos serviços de transporte aéreo", estar-se-iam violando os princípios constitucionais da dignidade humana, proporcionalidade e razoabilidade (sem, no entanto, existirem maiores elucubrações sobre o porquê de tais violações). Afirmou-se que a redução do prazo para arrependimento da compra de passagens aéreas (para vinte e quatro horas) iria de encontro ao que prescreve o artigo 49 do CDC (sete dias) e que a regra que prevê o não cancelamento automático do trecho de volta pelo transportador (no caso de não embarque do consumidor no trecho de ida) também seria uma prática abusiva.

De outro lado, a ACP n ${ }^{\circ}$ 0810187-28.2016.4.05.8300, em trâmite na 9a Vara Federal de Pernambuco, protocolada também pelo PROCON em desfavor da ANAC, encampa impugnações à Resolução com base nos artigos $5^{\circ}, \mathrm{IV} ; 9^{\circ}$, caput; $12, \S 1^{\circ}, \mathrm{I} ; 13, \S 1^{\mathrm{o}} ; 14$, caput e $\S 2^{\circ} ; 15$, $\S 1^{\circ}$ e $32, \S 2^{\circ}$, I e II.

Resumidamente, afirma na exordial que "o despacho de bagagem é gratuito para malas de até 23 (vinte e três) quilos em voos domésticos e para duas malas de até 32 (trinta e dois) quilos, cada uma, em voos internacionais"; e que "os fornecedores poderão, de maneira arbitrária e sem qualquer controle, alterar o limite de peso para menor, podendo o fazer sob qualquer justificativa", dentre outras ilações.

Por fim, em relação à ACP $\mathrm{n}^{\mathrm{o}}$ 0000752-93.2017.4.01.3400 (pendente na $4^{\mathrm{a}}$ Vara Federal do Distrito Federal), manejada pelo Conselho Federal da Ordem dos Advogados do Brasil (CFOAB) em desfavor da ANAC, postulou-se a anulação dos artigos 13, caput; 15 e 45, da Resolução, com o viso de fazer a Agência se abster de autorizar a cobrança por bagagem dentro dos limites da franquia estabelecidos na legislação anterior.

Com o propósito de conduzir o presente artigo ao pragmatismo necessário das pesquisas jurídicas, enquanto ciência social aplicada, resolveu-se pontuar neste tópico o desenvolvimento das críticas específicas à Resolução $\mathrm{n}^{\circ} 400$ da ANAC, elegidas pelo órgão de defesa do consumidor na $\mathrm{ACP} \mathrm{n}^{\mathrm{o}}$ 0816363-41.2016.4.05.8100 (a que primeiro foi ajuizada, em curso na Justiça Federal do Ceará e que, possivelmente, será declarada preventa em relação às demais), de modo 
a promover reflexões e eventuais contrapontos, com lastro na teoria desenvolvida em epígrafe e nas conclusões da Nota Técnica n 19(SEI)/2016/GCON/SAS, visando ambientar o leitor à complexa dinâmica de tutela do consumidor em juízo.

Em relação ao artigo $3^{\circ}$ da norma setorial, tem-se uma previsão de que seja disponibilizada ao menos uma tarifa e que a multa pelo reembolso ou remarcação não ultrapasse $5 \%$ do valor total dos serviços de transporte aéreo. A disposição é atacada sob o argumento de que representaria uma vantagem manifestamente excessiva, na forma do artigo 39, V, do CDC e de que extrapolaria a inteligência do $\S 3^{\circ}$ do artigo 740 do CC-02, que dispõe sobre o direito rescindir o contrato de transporte e da restituição do valor da passagem (desde que feita a comunicação ao transportador em tempo de ser renegociada), tendo o transportador direito de reter até cinco por cento da importância a ser restituída.

Diferente do que alega o órgão de defesa do consumidor, imagina-se que opção regulatória da ANAC buscou conferir concretude ao disposto no Código Civil, conferindo mais liberdade de escolha ao consumidor, que poderá optar entre contratar a tarifa mais cara, com a compensação de uma multa menor nos casos de remarcação e reembolso, ou contratar aquela de preço mais acessível e convidativo, mas que, de outro lado, imponha maiores restrições nos casos de remarcação e reembolso.

Fato é que submeter todas as tarifas a esse teto comum de multa afrontaria o direito de escolha do consumidor e implicaria a situação de elevação do valor da prestação de serviços aéreos, deturpando a própria mens legis do $\S 3^{\circ}$, do artigo 740 do $\mathrm{CC}-02$, conforme atesta sua exposição de motivos, que é expressa ao afirmar que o código tem caráter genérico e deve se coadunar com a legislação especializada aplicada ao caso, servindo tal norma apenas como uma orientação aos agentes reguladores do transporte. Logo, entende-se que sua aplicação deve ser condicionada às condições que o mercado se sujeita e aos regulamentos incidentes.

Acrescente-se que a lógica do transporte aéreo dificulta a aplicação do preceito geral civilista, pois o legislador não estabeleceu o tempo razoável à renegociação, impossibilitando o passageiro de dispor de tempo suficiente para a renegociação.

Imagina-se que com a manutenção do artigo $3^{\circ}$, conseguir-se-á respeitar as práticas comerciais do setor, que visam assegurar preços mais baixos aos consumidores, tendo em vista que se trata de uma dinâmica salutar ao setor, contribuindo para que o transportador tenha certeza dos clientes que irá transportar, podendo assim fazer ofertas a preços mais baixos, com restrições mais altas para alterações e cancelamentos. A limitação de todas as multas contratuais a patamares mínimos impediria a diferenciação dos serviços e o gerenciamento tarifário, acarretando aumento do preço das passagens para todos, independentemente da antecedência da aquisição.

Quanto ao artigo $9^{\circ}$ da norma em testilha, direcionado à especificação das multas contratuais, que não poderão ultrapassar o valor dos serviços de transporte aéreo, limita-se o órgão demandante a atacar o dispositivo por entender que a conduta se insurge contra os princípios da dignidade da pessoa humana, proporcionalidade, razoabilidade dentre outros. Defende, ainda, que a norma em análise diverge do suposto papel das Agências, em que se incluiria a proteção do consumidor.

Salvo melhor juízo, entende-se neste caso que a norma setorial tende a proteger o consumidor, diferente do que professa a entidade demandante, tendo em vista que a norma trata de um teto e não de uma regra geral de que a multa, em todas as situações e em todas as tarifas, deverá ser equivalente a esse valor, na esteira do que já prescrevia o artigo 412 do CC-02 ("o valor da cominação imposta na cláusula penal não pode exceder o da obrigação principal”), não sendo 
demais lembrar que os serviços de transporte aéreo já estão sujeitos ao regime da liberdade tarifária (artigo 49 da Lei 11.182/2005).

Outra norma impugnada na ação coletiva foi artigo 11, que trata da desistência da passagem adquirida, a qual poderá ser realizada, sem ônus, desde que feita no prazo de 24 (vinte e quatro) horas, a contar do recebimento do comprovante. Na óptica do PROCON cearense, o artigo fere o disposto no artigo 49 do CDC, o qual prevê o prazo de 7 (sete) dias para o exercício do direito de arrependimento para compras realizadas fora do estabelecimento comercial.

Estudando com mais vagar os debates plurais (com vários segmentos da sociedade) que foram capitaneados pelo órgão regulador, tem-se que à luz da legislação revogada (Portaria $\mathrm{n}^{\circ}$ 676/00), previa-se a possibilidade de cancelamento até 4 (quatro) horas antes da hora estabelecida no bilhete de passagem (artigo 13), sem qualquer referência a uma modalidade de cancelamento em que não incidissem ônus aos usuários.

Com a normatização do Resolução $\mathrm{n}^{\circ} 400$, alinhou-se a norma setorial com o artigo 740 do CC-02, ampliando-se os direitos do usuário do transporte aéreo, na medida em que, juntamente com o artigo $9^{\circ}$ da Resolução, afasta-se qualquer ônus para o usuário que obedeça a liturgia que restou disciplinada.

Adite-se ao exposto o esclarecimento de que o artigo 49 do CDC destina-se apenas a compras remotas realizadas fora do estabelecimento comercial (quando, normalmente, o consumidor desconhece as qualidades do produto ou serviço que está adquirindo, sendo razoável que disponha de tal prazo para, uma vez tendo recebido e estando apresentado ao objeto da avença, possa aprazadamente se arrepender), ao passo que a norma em trato tem alcance mais amplo e se espraia a todos os contratos de transporte firmados, tanto no estabelecimento comercial, quanto por telefone ou internet, sendo de notar que normalmente o consumidor de transporte aéreo está diante de maior grau de inteligibilidade e transparência acerca das propriedades do serviço contratado.

Por fim, impugnou-se o disposto no artigo 19 da Resolução no 400, que disciplina a possibilidade de cancelamento do trecho de volta, nas passagens do tipo "ida e volta" em que o trecho inicial (de ida) não tenha sido utilizado. Professa o autor coletivo que a previsão regulatória também representaria prática abusiva (na esteira do artigo 39, V, do CDC) e configuraria apropriação indébita a atrair a aplicação do parágrafo único do artigo 42 da norma consumerista.

Mais uma vez, diverge-se da premissa teórica levada ao conhecimento do Judiciário. É que, mediante nova reflexão sobre a teoria das relações consumeristas, especialmente a intepretação das cláusulas restritivas dos contratos que tenham sido devidamente comunicadas aos clientes (artigo 54, $\S 4^{\circ}$, do CDC), verificava-se que, da parte das empresas, a perda de receita no voo de partida, somada com a alta probabilidade de no-show no voo de retorno, gerava o cancelamento automático do trecho de retorno, a fim de buscarem a maior taxa de ocupação possível das aeronaves e reduzir seus prejuízos.

Com a nova proposição normativa, prevê-se a alternativa do passageiro manter seu voo de retorno mediante comunicação ao transportador (o não aviso permitiria à empresa comercializar o trecho de volta e o tempo mínimo seria o horário original da partida do voo, levando-se em consideração a hipótese mais restritiva), tendo em vista os casos em que mesmo o passageiro não utilizando a ida, por imprevistos ou contingências pessoais, pode eventualmente ter interesse em usar a volta, utilizando-se de outra alternativa para chegar ao local de destino. Tal ilação tem o condão de equacionar as distintas necessidades do transportador e do passageiro, buscando não prejudicar o passageiro e ao mesmo tempo evitar perdas para as empresas que, indiretamente, se refletiam em maiores custos repassados ao consumidor final. 
A seguir, será abordada uma questão específica que também foi objeto da demanda coletiva, relacionada com a suposta abusividade na cobrança de franquias de bagagens.

\section{ANÁLISE APARTADA DA SUPOSTA PRÁTICA ABUSIVA NA COBRANÇA DA FRANQUIA DE BAGAGENS.}

Por questões didáticas, resolveu-se segregar a análise de um dos tópicos da ACP $\mathrm{n}^{\mathrm{o}}$ 0816363-41.2016.4.05.8100, notadamente o que impugna o artigo $4^{\circ}$, § $2^{\circ}$ da Resolução da ANAC (que dispõe acerca do valor final a ser pago, o qual deverá ser acrescido de eventuais serviços opcionais contratados ativamente pelo consumidor no processo de comercialização de passagem aérea), em face da enorme repercussão midiática que se capilarizou nas últimas semanas.

São consideradas abusivas as cláusulas que prejudicam nitidamente a parte mais fraca da relação, causando um desequilíbrio contratual, conforme se pode interpretar da norma contida no artigo 51 do CDC. Tal norma não estabelece um conceito, porém, enumera um rol (não exaustivo) de cláusulas que podem ser consideradas abusivas, com base, inclusive, no entendimento jurisprudencial.

Em que pese o Código não ter trazido o conceito de cláusula abusiva, este acabou sendo estabelecido pela doutrina de diversas formas. Otávio Luiz Rodrigues Junior (2006, p. 200), por exemplo, tem por abusiva a "cláusula opressiva, vexatória, onerosa ou excessiva".

O conceito formulado por Cristiano Heineck Schmitt (2010, p. 75), por sua vez, chama atenção para a quebra do sinalagma contratual ensejado pela estipulação de uma cláusula abusiva. Cláudia Lima Marques (2014, p. 984) segue no mesmo sentido, ao conectar a identificação da abusividade com a quebra da boa-fé objetiva, sendo a característica preponderante de uma cláusula abusiva prejuízo grave causado ao consumidor e o desequilíbrio resultante na relação contratual.

Observa-se que todos esses conceitos têm em comum o foco na vulnerabilidade do consumidor perante o fornecedor, que, ao inserir uma cláusula abusiva no contrato, torna-o excessivamente vantajoso para si, deixando o consumidor em uma situação exagerada de prejuízo e pondo fim ao equilíbrio contratual.

O PROCON entende que o dispositivo representaria uma prática abusiva, capitulada no artigo 39, V e X, ambos do CDC. A leitura que fez do citado dispositivo é de que este fora inserido tão somente para se conjugar com a desregulação da franquia de bagagem despachada (proposta pelo artigo 13 da Resolução), ensejando, assim, a ilegalidade da liberação da franquia de bagagem despachada, na conformidade do que prescreve o artigo 734 do CC-02, cuja interpretação autorizaria a tese de que o transporte de pessoas englobaria, necessariamente, o transporte de bagagem despachada.

O primeiro ponto a se destacar é que, hoje, o transporte da bagagem despachada não é gratuito. Uma vez que seu valor está inserido no preço da passagem, os passageiros hoje pagam indiretamente pela franquia. Consequentemente, o valor da bagagem despachada pago pelo passageiro não é transparente. O preço final para cada passageiro, então, é o valor de seu transporte aéreo mais os custos do transporte da bagagem despachada. Repise-se que as empresas de transporte aéreo já operam em regime de liberdade tarifária e, pela racionalidade econômica, não 
teriam por que não repassar, hoje, ao preço da passagem todos os custos do transporte da bagagem despachada.

Com o objetivo diametralmente oposto ao que alega o PROCON, entende-se que a norma pretende evitar que o passageiro seja cobrado por serviços que não foram contratados ativamente e evitar que caiba a ele desativar prestações opcionais ofertadas e cujo valor já seja incluído no valor da passagem. Quem não se lembra da prática utilizada nos sites de empresas aéreas em que o pretendo comprador da passagem tem que desabilitar o seguro de viagem, que já vem marcado automaticamente? Tal prática vai ao encontro da afirmação da autonomia da vontade do consumidor, privilegiando sua liberdade para contratar?

Ao que parece, o regulamento da ANAC visa coibir a prática lesiva ao consumidor de pré-selecionar serviços opcionais de forma sub-reptícia, tais como seguros de viagem, assentos mais caros (conhecidos como "assentos conforto"), entre outros, induzindo os passageiros a erro, pois adquiriam produtos que não desejavam. Esta é a regra chamada de opt-in e opt-out. Estes termos são comumente usados por empresas de marketing e designam regras de envio de mensagens. O usuário marca uma caixa de mensagem (opt-in) concordando com o recebimento das mensagens. Caso não marque (opt-out) indica que não aceita receber as mensagens. Este conceito foi ampliado para vendas de produtos via internet, dentre eles para vendas de bilhetes aéreos. Ela se inspira na prática regulatória do Departamento de Transportes dos Estados Unidos que, em 2011 estabeleceu padrões mínimos de proteção aos consumidores de transporte aéreo e legislou pela proibição da participação passiva do consumidor em relação a compra de produtos e serviços acessórios ao bilhete de passagem aérea.

Ao invés de promover uma desregulação da franquia de bagagem despachada, como defende o PROCON cearense, imagina-se que a desregulamentação da bagagem fomentaria o objetivo das viagens de baixo custo (low cost), que atualmente não são uma realidade no Brasil. A recém editada Resolução libera a franquia de bagagem despachada, cujas regras de transporte deverão ser previamente informadas ao passageiro e pactuadas entre as partes. Com isso, somente pagarão pela bagagem despachada os passageiros que efetivamente despacharem bagagem, permitindo que aqueles que não desejem despachar bagagem possam adquirir um bilhete em que o valor da bagagem despachada não esteja inserido.

No modelo atual, independentemente de se utilizar o limite de franquia para despacho de bagagem, o consumidor arca com os custos máximos pré-estabelecidos, revelando tratamento desigual na medida em que padroniza o perfil de passageiros, que têm repassados a si o custo operacional do serviço de despacho de bagagem, sempre incluso ao serviço de transporte de pessoas.

A Portaria $\mathrm{n}^{\circ}$ 957/GM-5/1989 estabelecia uma franquia de bagagem despachada de $30 \mathrm{~kg}$, para primeira classe, e $20 \mathrm{~kg}$ para as demais classes (salvo no caso da aviação regional, que era de $10 \mathrm{~kg}$ ). Os normativos que lhe sucederam (Portaria ${ }^{\circ}$ 676/CG-5/2000 e das NOSAIs CT-011/ 2000 e CT 012/2001) igualaram as franquias nacionais às oferecidas nos voos domésticos pela VARIG (que deteve por muitos anos a maior fatia do mercado brasileiro), com franquias obrigatórias de $30 \mathrm{~kg}$ ( $1^{\mathrm{a}}$ classe) e $23 \mathrm{~kg}$ (demais classes).

Atualmente, a imposição do oferecimento de $23 \mathrm{~kg}$ de bagagem despachada está muito além da média nacional, conforme revelou a Nota Técnica $\mathrm{n}^{\circ}$ 11/2016/GEAC/SAS, que aferiu a percentagem de $35 \%$ dos passageiros que são transportados sem bagagem, segundo dados da Secretaria de Aviação Civil do Ministério dos Transportes. Por meio de estudo do impacto econômico da medida, a ANAC apurou que o valor médio do peso da bagagem despachada em voos domésticos em 2015 fica próximo a 11,5kg (itens 5.36 a 5.43 da Nota Técnica $\mathrm{n}^{\mathrm{o}} 16(\mathrm{SEI}) / 2016$ / GCON/SAS), com a grande maioria das bagagens despachadas oscilando entre $5 \mathrm{~kg}$ e $16 \mathrm{~kg}$. O 
peso médio identificado é bastante próximo àquele garantido como bagagem de mão e sem incidência de cobrança adicional (10kg, conforme artigo 14 da Resolução). Mesmo assim, o custo do transporte das bagagens é rateado por todos, sem que isso precise constituir em uma obrigação aos passageiros.

Em relação ao benchmarking internacional, apurou-se através da Nota Técnica $\mathrm{n}^{\mathrm{o}} 11$ / 2016/GEAC/SAS, que poucos países do mundo têm intervenção estatal sobre transporte de bagagem, identificando-se o México (franquia de $25 \mathrm{~kg}$ para o transporte doméstico); a Rússia (franquia de $10 \mathrm{~kg}$, para o transporte doméstico ou bagagem de mão); e a China (franquia de $20 \mathrm{~kg}$, para o transporte doméstico). A par desse dado, nota-se que países de grande extensão territorial como África do Sul, Argentina, Austrália, Canadá, Colômbia, Estados Unidos e Índia, bem como todos os países da União Europeia ou países com território fragmentado no qual o transporte aéreo é um importante meio de deslocamento, como as Filipinas, não têm regulação estatal para franquia de transporte de bagagem.

Por fim, promovendo-se uma reflexão civilista acerca da alegada dissociação do transporte de bagagem despachada do contrato de transporte de passageiro (supostamente ancorada na Resolução $\mathrm{n}^{\circ}$ 400), em afronta ao artigo 730 do CC-02 ("pelo contrato de transporte alguém se obriga, mediante retribuição, a transportar, de um lugar para outro, pessoas ou coisas"), isso não procede, tendo em vista que a norma setorial garante o transporte de bagagem de mão (de até $10 \mathrm{~kg}$ ), esse sim vinculado ao contrato de transporte do passageiro. Quanto às demais bagagens, trata-se de contrato de natureza acessória. ${ }^{7}$

\section{CONCLUSÃO}

Após a densa reflexão que se procurou compartilhar com o leitor no presente artigo, acerca dos institutos de defesa do consumidor ligados às recentes alterações das regras do transporte aéreo, constata-se a impositiva ambientação que o estudante do tema deve ter com as disposições civilistas aplicadas à questão, dada a indiscutível centralidade do Código de Direito Material no enfrentamento dos assuntos relacionados à órbita privada.

A par disso, é imperioso que se reconheça que os princípios de defesa da concorrência têm como pano de fundo, além da aplicação do princípio constitucional da livre iniciativa, a defesa do destinatário final, a tutela do consumidor, o que conduz à ilação de que sem uma atuação efetiva dos órgãos de defesa da concorrência, maiores dificuldades teriam os direitos do consumidor de serem amplamente tutelados, dada a tendência de consolidação de oligopólios capazes de aguçar a vulnerabilidade técnica, econômica e informacional em desfavor do player fraco dessa relação.

As normas de defesa da concorrência resguardam a liberdade, preocupando-se em preservar a possibilidade de escolha entre mais de um fornecedor de produtos ou serviços, potencializando o princípio da autonomia da vontade, tão caro às tradições do direito privado e, por que não dizer, à própria teoria dos direitos fundamentais, haja vista se relacionarem intimamente com

\footnotetext{
7 Nos termos do artigo 222 do Código Brasileiro de Aeronáutica - CBAer, lei especial do setor de aviação civil brasileiro, "Pelo contrato de transporte aéreo, obriga-se o empresário a transportar passageiro, bagagem, carga, encomenda ou mala postal, por meio de aeronave, mediante pagamento". Importante esclarecer a diferença entre o transporte de carga e o transporte de bagagem, para que não pairem dúvidas sobre a natureza acessória do transporte de bagagem. $\mathrm{O}$ transporte de carga é feito de forma autônoma, prescindindo de contrato de transporte de passageiro para existir. Para ser efetuado, basta que o contratante faça o contrato de transporte de carga e seja emitido um conhecimento aéreo de carga (AWB - air waybill, em inglês), que é o documento probatório do contrato. Diferentemente, o contrato de transporte de bagagem inexiste sem um contrato principal.
} 
a afirmação do querer do homem, individualmente considerado, imiscuindo-se com uma dimensão de sua personalidade.

Importante que se frise que a proteção do consumidor não é uma reação contra o mercado, mas, na realidade, visa a sua própria preservação e adequado funcionamento, procurando solucionar algumas falhas por ele apresentadas. Assim, reconhece-se que a dinâmica dos contratos no âmbito do direito do consumidor, enquanto uma das disciplinas do direito privado, foge à concepção clássica de contrato. Tal conclusão advém de todo contexto histórico relacionado com fatores de ordem econômica, social e política que foram determinantes para o reconhecimento da especialização das relações consumeristas.

No caso concreto que se pretendeu analisar, viu-se que a retórica defendida pelo órgão de defesa do consumidor na ação coletiva foi no sentido de que a Agência Reguladora deveria restringir a liberdade do mercado de transporte aéreo proposta no Resolução $n^{\circ} 400$, a fim de supostamente defender este player fraco da relação, haja vista a provável exploração econômica que este virá a sofrer mediante a desregulação dos serviços.

Entendeu-se no presente arrazoado, porém, que a confessada desregulação do serviço de transporte aéreo, ao invés de fragilizar a condição do passageiro e aguçar a vulnerabilidade peculiar da respectiva relação de consumo, poderá ter efeitos diametralmente opostos, na medida em que a ampliação da concorrência tenderá a trazer mais opções de mercado, com passagens mais baratas, inclusive, de modo a contemplar os variados segmentos e perfis dos contratantes (tanto os passageiros quanto as empresas), fazendo que com seja possível a retomada de crescimento do setor, cuja manutenção das premissas normativas anteriores (concebidas historicamente em outra época, registre-se), impingia excessiva oneração aos contratantes.

\section{REFERÊNCIAS}

AGUIAR JÚNIOR, Ruy Rosado. O Acesso do Consumidor à Justiça no Brasil. Doutrinas Essenciais. v. VI. São Paulo: Revista dos Tribunais, 2011.

ALMEIDA. Gregório Assagra de. Direito Processual Coletivo Brasileiro: um novo ramo do direito processual (princípios, regras interpretativas e problemática da sua interpretação e aplicação). São Paulo: Saraiva, 2003.

AVERITT, Neil W.; LANDE Robert H. Consumer sovereignty: a unified theory of antitrust and consumer protection law. Antitrust Law Journal, n. 713, 1997. Disponível em: $<$ http://scholarworks.law.ubalt.edu/cgi/viewcontent.cgi? article=1366\&context=all_fac $>$. Acesso em: 11 nov. 2016.

AZEVEDO, Antonio Junqueira. O Direito Pós-Moderno e a Codificação. Doutrinas Essenciais. São Paulo: Revista dos Tribunais, 2011.

BAUDRILLARD, Jean. A sociedade de consumo. 2. ed. Tradução de Artur Mourão. Portugal, Lisboa: Edições 70, 2008.

BAUMAN, Zygmunt. A vida em fragmentos: sobre a ética pós-moderna. Tradução de Alexandre Werneck. Rio de Janeiro: Jorge Zahar, 2011.

BECK, Ulrich. Sociedade de risco: rumo a uma outra modernidade. Tradução de Sebastião Nascimento. Rio de Janeiro: Editora 34, 2011.

BORK, Robert H. The antitrust paradox: a policy at war with itself. New York: The Free Press, 1993. 
BRASIL. Comando da Aeronáutica. Portaria n. 957/GM-5/1989.

Comando da Aeronáutica. Portaria n. 676/CG-5/2000 e das NOSAIs CT-011/2000 e $\overline{\text { CT } 012 / 2001 . ~}$

. ANAC. Nota Técnica n. 16(SEI)/2016/GCON/SAS.

. ANAC. Nota Técnica n. 11/2016/GEAC/SAS.

CAPPELLETTI, Mauro. O Acesso dos Consumidores à Justiça. Doutrinas Essenciais. v. II. São Paulo: Revista dos Tribunais, 2011.

DELGADO, Mário Luiz e outros. Código Civil e codificação. In: CASSETARI, Christiano (coord.). 10 anos de Vigência do Código Civil Brasileiro de 2002 - Estudos em Homenagem ao professor Carlos Alberto Dabus Maluf. São Paulo: Saraiva, 2013.

FONSECA, João Bosco Leopoldin. Lei de proteção da concorrência. Rio de Janeiro: Forense, 2001.

GARCIA, Leonardo de Medeiros. Código de Defesa do Consumidor Comentado artigo por artigo. 12. ed. Salvador: Juspodium, 2016.

GOMES, Orlando. Contratos. 18. ed. Rio de Janeiro: Forense, 1999.

GRINOVER, Ada Pellegrini. Significado Social, Político e Jurídico da Tutela dos Interesses Difusos. Revista de Processo, v. 97, 2000, jan./mar. 2000.

. O Novo Processo do Consumidor. Doutrinas Essenciais do Consumidor. v. 6. São Paulo: Revista dos Tribunais, 2011.

LACEY, Eladio. Autoria Singular e Coletiva nas Infrações contra o Meio Ambiente e as Relações de Consumo. Revista de Direito do Consumidor, v. 22, abr./jun. 1997.

MAGALHÃES, Francisco Carlos. Leis que preservam a concorrência protegem o consumidor. CADE, Brasília, ano II, n. 5, p. 3-5, dez. 1976.

MALARD, Neide Terezinha. Concentração de empresas: livre concorrência e livre iniciativa. Dissertação (Mestrado em Direito), Faculdade de Direito, Universidade de Brasília (UNB), Brasília, 1997.

MARQUES, Cláudia Lima. Três tipos de diálogos entre o CDC e o CC-02: superação das antinomias pelo diálogo das fontes. In PFFEIFFER, Roberto; PASQUALOTTO, Adalberto (orgs.). CDC e CC-02: convergências e assimetrias. São Paulo: Revista dos Tribunais, 2005.

. Contratos no Código de Defesa do Consumidor: o novo regime das relações contratuais. 7. ed. São Paulo: Revista dos Tribunais, 2014.

et al. Comentários ao Código de Defesa do Consumidor. 3. ed. São Paulo: Revista dos Tribunais, 2010.

MIRAGEM, Bruno Nubens Barbosa. Nulidade das Cláusulas Abusivas nos Contratos de Consumo: Entre o Passado e o Futuro do Direito do Consumidor Brasileiro. Revista de Direito do Consumidor, v. 72.

NUNES, Luis Antonio Rizzatto. Curso de direito do consumidor. 7. ed. São Paulo: Saraiva, 2012.

PASQUALOTTO, Adalberto. A Defesa Coletiva dos Consumidores no Brasil. Doutrinas Essenciais do Consumidor. v. 6. São Paulo: Revista dos Tribunais, 2011. 
PFFEIFFER, Roberto Augusto Castellanos. CDC e serviços públicos: balanços e perspectivas. In MIRAGEM, Bruno; MARQUES, Claudia Lima; OLIVEIRA, Amanda Flávio de. 25 anos do CDC: trajetórias e perspectivas. São Paulo: RT, 2016.

RODRIGUES JUNIOR, Otavio Luiz. Revisão judicial dos contratos: autonomia da vontade e teoria da imprevisão. 2. ed. São Paulo: Atlas, 2006.

SALOMÃO FILHO, Calixto. Direito concorrencial: as condutas. São Paulo: Malheiros, 2003.

SCHMITT, Cristiano Heineck. Cláusulas abusivas nas relações de consumo. 3. ed. São Paulo: Editora Revista do Tribunais, 2010.

THEODORO JÚNIOR, Humberto. Contratos - Princípios Gerais - Tendências do Direito Contratual Contemporâneo - Abrandamento dos Princípios Tradicionais - Intervenção Estatal Crescente - Impacto do Código de Defesa do Consumidor. Doutrinas Essenciais do Consumidor. v. 1. São Paulo: Revista dos Tribunais, 2011.

WATANABE, Kazuo. Demandas Coletivas e os Problemas Emergentes da Práxis Forense. Doutrinas Essenciais do Consumidor. v. 6. São Paulo: Revista dos Tribunais, 2011. 